\title{
Modern Aristotelianism
}

\section{By Prof. H. Levy, Imperial College of Science, London}

$\mathrm{D}^{\mathrm{n}}$ R. H. DINGLE's plea in Nature of May 8 for a return to experimental criteria in science, is timely. One may differ from him over the grounds upon which it rests, or over the stress he places on certain points : it is difficult to imagine any genuine disagreement with his main contention.

It must be realized, however, that since the days of Galileo, much has happened in science, not only in the extent of the fields that have been explored, in the nature of the instruments that have been designed to facilitate investigations, but also in our understanding of the relation between the subject matter of science, and those who pursue its study. It is never easy for those who are absorbed in the detailed technique to appreciate the philosophy and the methodology underlying their practice, or even to recognize when and why they are establishing new traditions. To-day we are witnessing such changes, and Dr. Dingle's protest will have been effective if it has the effect of forcing us to examine, in an objective way, the path that is being trodden.

Mathematics is one of the instruments the power of which since the days of Galileo has reached a completely new level. Its success in analysing the relations between empirical data, and in exploring the implications of speculative theories, has tended so to impress the mind, not of the mathematician alone, as to confer on it almost the status of an independent and self-constituted science. It is in directing attention to this dangerous intoxication with symbols that Dr. Dingle's protest is well-founded.

This situation is, however, not to be met merely by a reiteration of the Galilean basis of science, as Dr. Dingle does, or by falling into the error of identifying physics with the whole of science, as Dr. Dingle, following the lead of the mathematician, also does, but demands a positive statement of the place of mathematics and its attendant speculations in the process we call science.

For mathematics is essentially an instrument of discovery, and no instrument that has to tell us about the behaviour of the world can function in a vacuum. It works on something, and that something must be extracted from the experience of men in the objective world. Now the trouble begins to show itself in the first instance in the fact that the mathematician can handle ideas and speculations apparently divorced from any empirical background. He starts with given assumptions convenient to himself and his mathematical equipment. I say apparently with deliberation, because since the mathematical craftsman is primarily interested in the logical coherence of his analysis, he and those others who cannot follow his intricate symbolism, find themselves less and less disposed to examine the origin of the ideas on which he is experimenting with his mathematics. "Mathematies," he would say, "is the formulation of rational relations between any given set of ideas." $\mathrm{He}$ does not inquire whence the ideas come, what material circumstances in the world about him have stimulated them, how far they are a direct reflection of the changing situation in the objective world, or how far they are simply a novel combination of such stimulated ideas. As soon as this issue is raised, we can see how futile it is to tilt at the a priori principles of the Aristotelians; there are none. What has to be exposed to view is the human experiential basis on which the principles unconsciously rest.

If it is true that the given ideas of the mathematician do not come as a miracle out of the void, that they are in some sense 'transformed' observations, then whatever assertions he may make that he can dispense with observations, he is nevertheless pursuing an aspect of inquiry subsumed under the phase-"The formulation of rational relations between 'transformed' sense observations". How close this seems to be to Dr. Dingle's position, judging from his statements, as he judges from those of Prof. Milne, may be seen by comparing this phrase with his own definition of science :

"Science is the formulation of rational relations between sense observations."

Like Sir Arthur Eddington, however, Dr. Dingle is better than his definition, for what he is really pleading for is something slurred over in his definition, the conscious interplay and mutual directiveness between theory and experiment. Every theory and every experiment rests on an interwoven history of both. "Science," one might have expected him to assert, "is the empirical-cum-rational analysis and directing of natural process." Of course, even the speculative cerebrations of mathematicians are natural processes, and in that sense the subject of scientific interest, not to physicists, but to psychologists ; or, when a mathematician asserts that by thought alone (whatever that is) the whole of physics can be deduced, of interest to medical psychologists. What we are here concerned with is the results of that cerebration, because they purport to state something about physics.

Two criteria are required in their examination. One will enable us to judge when results are such as to justify incorporation in the expanding body of scientific fact and generalization. That test is a practical one, and in the final analysis must be applied by the experimenter. Even a theory based on so-called a priori principles, where it purports to express itself in terms of observables, can have this test applied to it. Where it cannot be so expressed, it does not fall within the ambit of science: it is mathematically experimental speculation. Provided we recognize its nature and do not attempt to dress it up in the outward guise of science, who can assert that the experience so gained is of no value in the pursuit of legitimate science? It is the emergence of this class of inquiry that distinguishes the present epoch in mathematical physics from that of Galileo.

To assert that such studies may have a secondary place in suggesting other more directly scientific inquiries does not provide the justification for their indiscriminate pursuit. Some other criterion must be found. ". . . hundreds of pages, and thousands of pounds are being spent ... by a growing army of 'research' workers . . ." writes Dr. Dingle as 
evidence of the folly of the new vogue in universes. Here the appeal is certainly not to any criterion directly or indirectly implied in his definition of science, but to a social judgment. He points the finger at something which he conceives, rightly or wrongly, to be anti-social, because it involves wastage on studies not directly scientific. This is a very significant matter. It is importing a consideration that has become more and more prominent in the columns of scientific journals during the past few years. It asserts that the justification for a scientific inquiry is not entirely a narrow scientific one but rests also on its social value. It is an admission of the interconnexion of science with society, that the direction of scientific development, and therefore that the body of theory and practice embraced within science at any given time, is dependent on fundamental social, besides scientific, considerations. That he makes this judgment is itself a fact : hence on his own definition of science he must find a rational place for it within that definition. As it stands there is none. If he objects to the work of the mathematical speculators, he can do so at present only with respect to these phrases that purport to deny the necessity for observation. He cannot object to the expenditure of funds on such investigations, or to publications that are simply mathematical exercises in fictitious model universes.

Just as soon as we face up to this, these various problems begin to fall into a more integrated scheme. We state the position thus:

(1) Science is a social effort to understand, control and fashion Nature in accordance with developing human needs and desires.

(2) The method of science is an ever-growing and ever-deepening integration between experiment and inference, emerging in successive generalizations and successive applications to practice.
(3) Mathematics is an instrument designed to assist in the drawing of inferences from sets of data or of ideas, or what amounts to the same thing, to test such sets for their logical consistencies and inconsistencies. It is in the exposure of the latter that the deficiencies in the original data are made plain. Out of these deficiencies emerges a drive towards further experimentation.

Now when the mathematics under (3) can be regarded as accessory to the inferential processes of (2), and so can be integrated with experimental development, it can be said to have a place in science. This would include that part of pure mathematics that in the widest possible sense can be looked upon directly or indirectly as 'instrument-making'. In no circumstances can (3) ever replace (2).

To decide that a particular series of investigations ought to be encouraged, and, in particular, that it ought to receive the blessing of dominant scientific groups-and this is ultimately the question raised by Dr. Dingle-equally implies deciding to discourage other investigations, since the income to science is limited. Such a decision can emerge only from a thoroughly clear conception of what is implied in (1). It involves planning science pure and applied in its social context, and not following it indiscriminately for intellectual, financial or æsthetic interest; we are very far from that at the present moment, as the leader columns of NaTURE amply testify. Dr. Dingle is therefore tilting at one of the irrational features of social and scientific life. The fact that such irrationalism manifests itself in bold assertions of the type Dr. Dingle rightly deplores, that (3) can replace (2), is in such circumstances a natural consequence of the persistent refusal of scientific men to devote as much careful thought to science as a movement as they are prepared to give to their specialized fields.

\section{Royal Observatory, Greenwich Annual Visitation}

$\mathrm{T}$ HE annual visitation of the Royal Observatory, Greenwich, by the Board of Visitors took place on June 5.

The report of the Astronomer Roval includes for the first time an account of the work of the Nautical Almanac Office, which has been made a branch of the Observatory, with Mr. D. H. Sadler as a chief assistant and superintendent of the Office. It is of interest to recall that the Nautical Almanac originated with Maskelyne, the first volume appearing in 1765 , the year following his appointment as Astronomer Royal, and that the almanacs for fifty years were produced under his direction.

The Nautical Almanac Office has recently undertaken the compilation of an Air Almanac, specially adapted to the requirements of aerial navigation. The first issue will cover the last three months of the present year. The Air Almanac will give the air navigator the astronomical data in a convenient form; but the present methods for the subsequent computation are not suitable for conditions in the air. Extensive altitude and azimuth tables will be computed in the Office, which will give the solution of the spherical triangle directly.
The astronomical observations at Greenwich during the past year suffered inevitably from the poor observing conditions, the year having been one of the most cloudy on record. 6,573 transit observations were obtained, including 107 observations of the sun and 86 observations of the moon. The observations of the moon continue to show a decrease in the correction required by the longitude according to Brown's tables. These tables, however, include Newcomb's great empirical term and, when comparison is made with pure gravitational theory, the moon shows an increasing departure from its computed place. This departure is produced by variations in the rate of rotation of the earth. The accumulated effect of such variations in a year may at times amount to one second. The best astronomical clocks are scarcely sufficiently uniform in rate to detect such an error. It is possible that a clock of the vibrating quartz crystal type would have the desired accuracy. Such a clock is under construction for the Observatory at the National Physical Laboratory and should be of material help in improving still further the accuracy of the time signals sent out from the Observatory, which are necessarily based on predicted clock errors. 